\title{
PERANCANGAN SISTEM APLIKASI INVENTORI BAHAN BAKU PADA PT TAYOH SARANA SUKSES BERBASIS JAVA
}

\author{
Rama Dwi Prana ${ }^{1}$, Andi Dwi Pangestu ${ }^{2}$, Puput Irfansyah ${ }^{3}$ \\ Program Studi Teknik Informatika, Fakultas Teknik dan Ilmu Komputer, \\ Universitas Indraprasta PGRI \\ Jalan Raya Tengah No 80, Kelurahan Gedong, Pasar Rebo, Jakarta Timur \\ ramadwiprana@gmail.com¹, andi.dwipangestu@gmail.com², irfandot@gmail.com
}

\begin{abstract}
Abstrak
PT Tayoh Sarana Sukses menjalin kerjasama dengan beberapa supplier yang menerima bahan mentah untuk menambah stok bahan baku didalam perusahaan, bahan baku tersebut digunakan untuk menjalankan proses produksi. Dalam mengelola data supplier dan data persediaan bahan baku PT Tayoh Sarana Sukses sering mengalami beberapa masalah seperti data supplier yang tidak terdata dengan baik, data stok bahan baku yang tidak sama dengan stok bahan baku yang ada di gudang produksi. Adapun rumusan masalahnya seperti cara agar supplier terdata dengan baik, cara mengatasi stok bahan baku yang berbeda dengan stok yang ada di gudang, cara membuat laporan yang terkomputerisasi dan hemat waktu. Penelitian ini bertujuan untuk membangun sistem inventori yang dapat membantu dalam proses kerja dan mengurangi kesalahan kerja. Metodologi penelitian yang digunakan dalam sistem pengolahan data yaitu teknik pengumpulan data seperti wawancara dan observasi. Dari penelitian ini dapat disimpulkan bahwa PT Tayoh Sarana Sukses memerlukan sebuah sistem yang dapat meminimalisir kesalahan dalam melakukan pendataan bahan baku. Oleh karena itu peneliti membuat sebuah sistem yang dapat melakukan pendataan secara terkomputerisasi.
\end{abstract}

Kata Kunci :Sistem Aplikasi Inventori, Bahan Baku, Berbasis Java

\begin{abstract}
PT Tayoh Sarana Sukses cooperates with several suppliers who receive raw materials to increase the stock of raw materials within the company, these raw materials are used to carry out the production process. In managing supplier data and raw material inventory data, PT Tayoh Sarana Sukses often experiences several problems such as supplier data that is not properly recorded, raw material stock data that is not the same as the stock of raw materials in the production warehouse. As for the formulation of the problem, such as how to keep suppliers well-recorded, how to deal with raw material stocks that are different from the stock in the warehouse, how to make computerized reports and save time. This study aims to build an inventory system that can assist in the work process and reduce work errors. The research methodology used in the data processing system is data collection techniques such as interviews and observations. From this research it can be concluded that PT Tayoh Sarana Sukses requires a system that can minimize errors in collecting raw material data. Therefore, the researcher create a system that can perform computerized data collection.
\end{abstract}

Keyword :Inventory Application System, Raw Material, Java Based

\section{PENDAHULUAN}

Persediaan merupakan stok bahan baku yang diperlukan agar proses produksi dapat berjalan, produksi itu sendiri ditujukan untuk memenuhi target produksi ataupun permintaan dari pelanggan. Dalam kelancaran produksi tentunya persediaan bahan baku sangatlah penting, oleh karena itu setiap perusahaan harus memperhatikan dengan baik tentang persediaan bahan baku yang ada.

Rumusan masalah penelitian ini adalah memecahkan permasalahan yang ada dalam perusahaan seperti data supplier dan data bahan baku yang tidak terdata dengan baik, dan proses pembuatan laporan yang belum terkomputerisasi.

Tujuan penelitian ini adalah agar pengolahan data supplier dapat terdata dengan lebih baik dan jelas,mengontrol jumlah bahan baku lebih rinci dan mengurangi kesalahan dalam perhitungan stok bahan baku, dan mempercepat proses pembuatan laporan yang dapat memaksimalkan waktu kerja dan proses produksi. Manfaat hasil penelitian dalam masyarakat diharapkan dapat menjadi 
tambahan atau masukan bahan referensi untuk penelitian selanjutnya dan juga dapat membantu PT Tayoh Sarana Sukses dalam melakukan pendataan bahan baku.

Perancangan yang sesungguhnya merupakan suatu aktivitas rekayasa perangkat lunak yang dimaksud untuk membuat keputusan-keputusan utama bersifat structural (Pressman, 2010). Sistem dapat diartikan sebagai kumpulan atau himpunan dari unsur, kompenen, atau variabel yang terorganisasi, saling berinteraksi, saling tergantung satu sama lain dan terpadu (Sutabri, 2012). Perancangan sistem adalah suatu fase dimana diperlukan suatu keahlian perancangan untuk elemen-elemen komputer yang akan menggunakan sistem, yaitu pemilihan peralatan dan program komputer untuk sistem yang baru (Kristanto, 2013).

Aplikasi adalah software yang dibuat oleh suatu perusahaan komputer untuk mengerjakan tugastugas tertentu, misalnya Microsoft Word, Microsoft Excel (Pipin, 2013). Persediaan dapat diartikan sebagai barang-barang yang disimpan untuk digunakan atau dijual pada masa atau periode yang akan datang. Persediaan terdiri dari persediaan bahan baku, persediaan bahan setengah jadi dan persediaan barang jadi (Ristono, 2013). Bahan yang dipergunakan dalam proses produksi pada periode yang bersangkutan, pengunaan bahan baku pada perusahaan biasanya diperoleh dari pembelian lokal, pembelian import atau bisa jadi dari pengolahan sendiri (Jayaatmaja, 2010). Persediaan bahan baku adalah persediaan bahan baku mentah yang akan diproses dalam proses produksi (Herjanto, 2010).

Use Case Diagram adalah diagram yang bersifat status yang memperlihatkan himpunan use case dan aktor-aktor (Murad, 2013). Java merupakan Bahasa pemrograman berorientasi objek yang sintaksnya mengikuti bentuk Bahasa $\mathrm{C}$ dan $\mathrm{C}++$ sehingga bagi programmer Bahasa $\mathrm{C}$ tidak akan kesulitan ketikan akan bermigrasi ke bahasa java karna sintaksnya hampir sama (Utomo, 2013).

XAMPP adalah paket software yang didalamnya sudah terkandung web server apache, database MySQL dan PHP interpreter (Wardana, 2010).

\section{PENELITIAN RELEVAN}

Penelitian yang dilakukan oleh (Wibowo, 2013) yang berjudul Sistem Informasi Inventory Sparepart Mobil Menggunakan Java Desktop pada Studi Kasus Kusuma Motor Kartasura. Penelitian ini bertujuan untuk merancang sistem informasi penjualan dan pendataan sparepart mobil pada toko Kusuma berbasis desktop agar suatu pelayanan penjualan sparepart tidak membutuhkan waktu yang lama. Mengelola pendataan stok barang dan jenis sparepart mobil dalam bentuk sistem informasi berbasis desktop.

Penelitian yang dilakukan oleh (Irnawati, 2017) yang berjudul Perancangan Program Persediaan Barang Dengan Java Desktop Pada PT PAKARTEL. Penelitian ini bertujuan untuk merancang program terkomputerisasi sebagai solusi permasalahan yang timbul akibat pengolahan data secara manual. Diharapkan dengan merubah sistem menjadi terkomputerisasi sehingga pengelolaan persediaan barang lebih efektif dan efisien, penyajian laporan persediaan barang menjadi lebih akurat dan tepat waktu.

\section{METODE PENELITIAN}

Penelitian kualitatif merupakan penelitian yang digunakan untuk menyelidiki, menemukan, menggambarkan, dan menjelaskan kualitas atau keistimewaan dari pengaruh sosial yang tidak dapat dijelaskan, diukur atau digambarkan melalui pendekatan kuantitatif (Saryono, 2010).

Metode pengumpulan data yang digunakan, antara lain :

Metode Observasi adalah metode mengumpulkan data melalui metode observasi merupakan aktivitas terhadap suatu proses atau obyek dengan maksud merasakan dan kemudian memahami pengetahuan dari sebuah fenomena berdasarkan pengetahuan dan gagasan yang sudah diketahui sebelumnya.Metode Wawancara adalah metode mengumpulkan data dengan metode wawancara yang merupakan percakapan antara dua orang atau lebih dan berlangsung antara narasumber dan pewawancara. 


\section{HASIL DAN PEMBAHASAN}

\section{Analisa Permasalahan}

Setelah melakukan penelitian maka dihasilkan analisa permasalahan sebagai berikut :

1. Data Supplier yang bekerja sama dengan PT Tayoh Sarana Sukses belum mempunyai sistem pendataan yang baik.

2. Stok bahan baku pada PT Tayoh Sarana Sukses berbeda dengan Data Stok yang ada.

3. Pembuatan laporan masih manual sehingga memperlambat proses kerja.

\section{Alternatif Penyelesaian Masalah}

Setelah melakukan penelitian maka dihasilkan alternatif penyelesaian permasalahan sebagai berikut:

1. Membangun sistem yang dapat mendata data supplier dengan baik

2. Membangun sistem pendataan bahan baku yang akurat serta terorganisir dengan baik, serta melakukan pengawasan secara teliti terhadap stok yang ada.

3. Membuat sebuah sistem yang dapat mencetak laporan secara cepat agar dapat memaksimalkan waktu kerja dan mempercepat proses produksi.

\section{Aturan Bisnis Sistem Yang Diusulkan}

Untuk memaksimalkan kinerja sistem agar meminimalisir kesalahan yang terjadi maka diperlukan sebuah tindakan, Adapun aturan bisnis sistem yang diusulkan sebagai berikut :

1. Pada saat barang dari supplier datang, data supplier langsung dimasukan kedalam sistem.

2. Memperbarui status stok digudang dengan cara melakukan input data di sistem data barang masuk dan keluar serta memberikan laporan apabila ada barang yg masuk dan keluar dengan begitu dapat mengurangi kesalahan penghitungan jumlah stok barang.

3. Pencetakan secara terkomputerisasi pada saat melakukan transaksi seperti barang masuk dan keluar, pencetakan laporan data stok, dan laporan data supplier, hal ini membuat lebih efisien dan menghemat waktu.

\section{UML(Unified Modeling Language)}

Berikut ini penggambaran tentang Sistem Aplikasi Inventori Bahan Baku Inventori Bahan Baku Pada PT Tayoh Sarana Sukses Berbasis Java dalam Diagram sebagai berikut :

\section{Use Case Diagram}

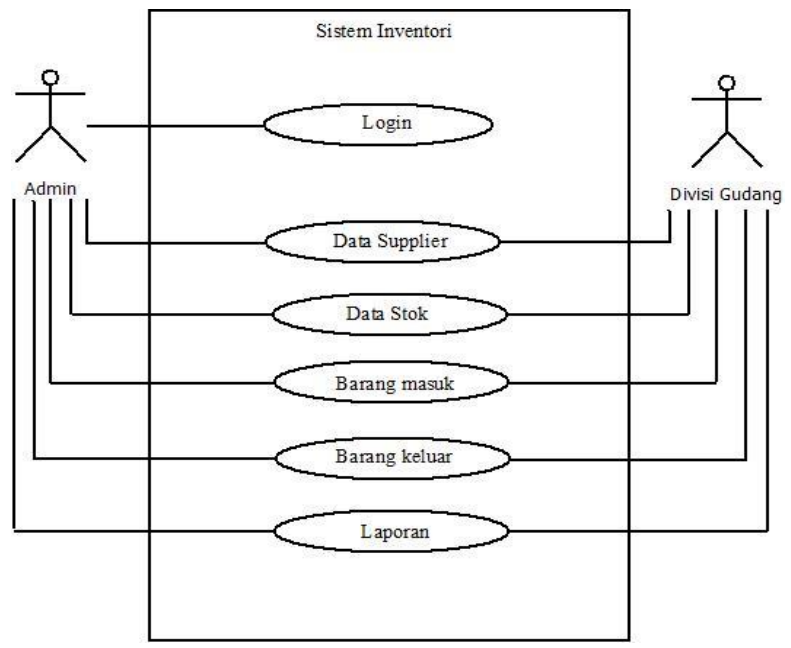

Gambar 1.Use Case Diagram 


\section{Activity Diagram}

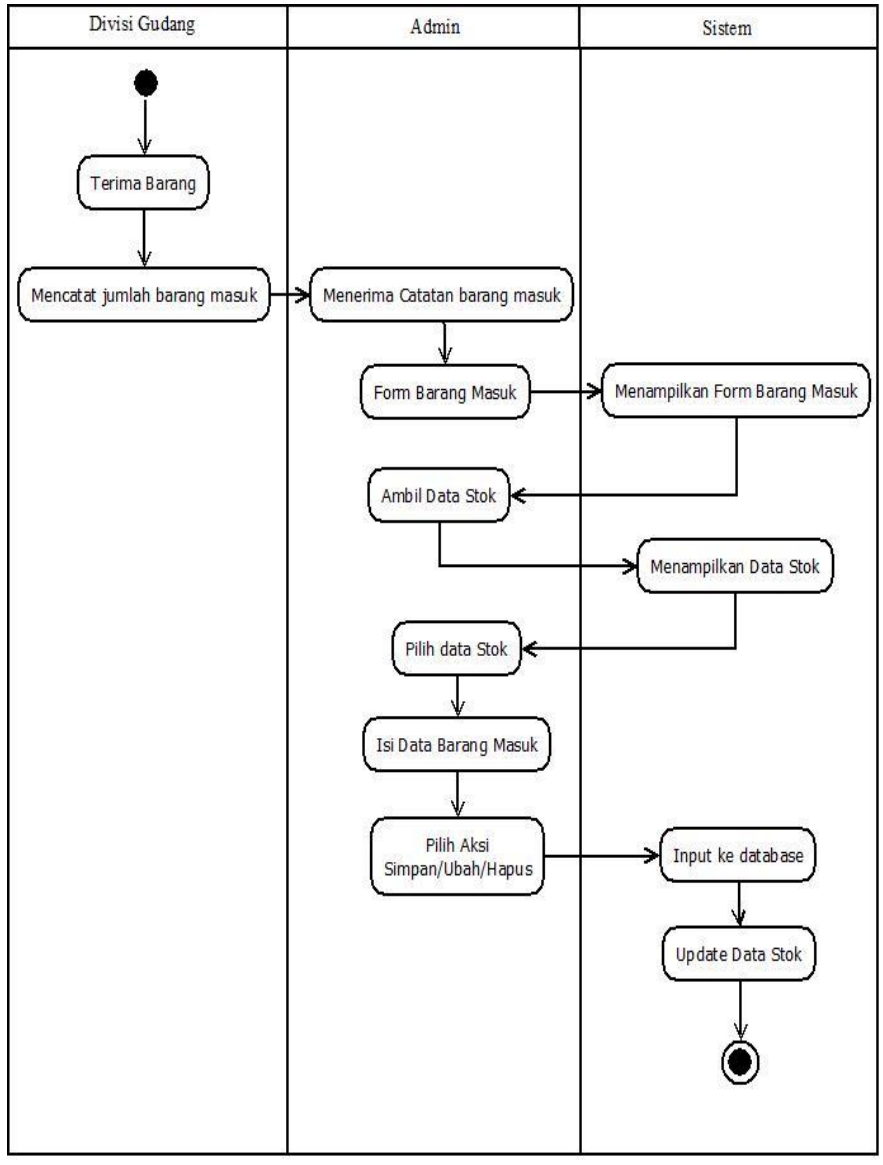

Gambar 2. Activity Diagram

\section{Class Diagram}

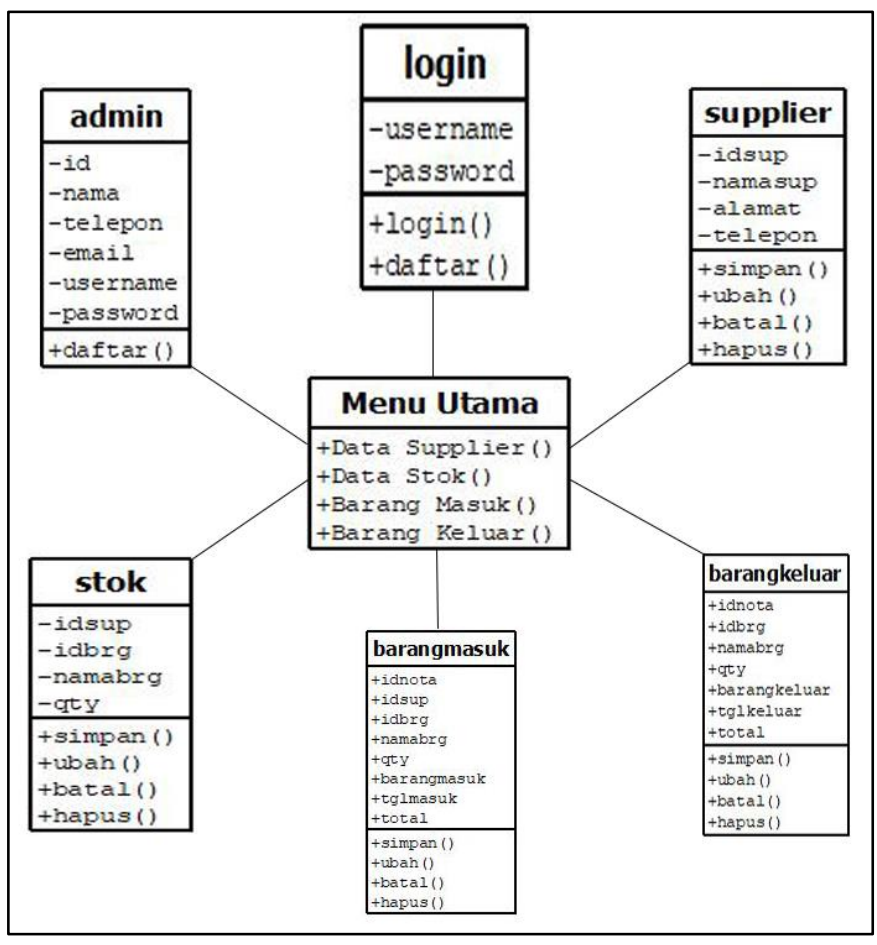

Gambar 3. Class Diagram 


\section{Tampilan Layar}

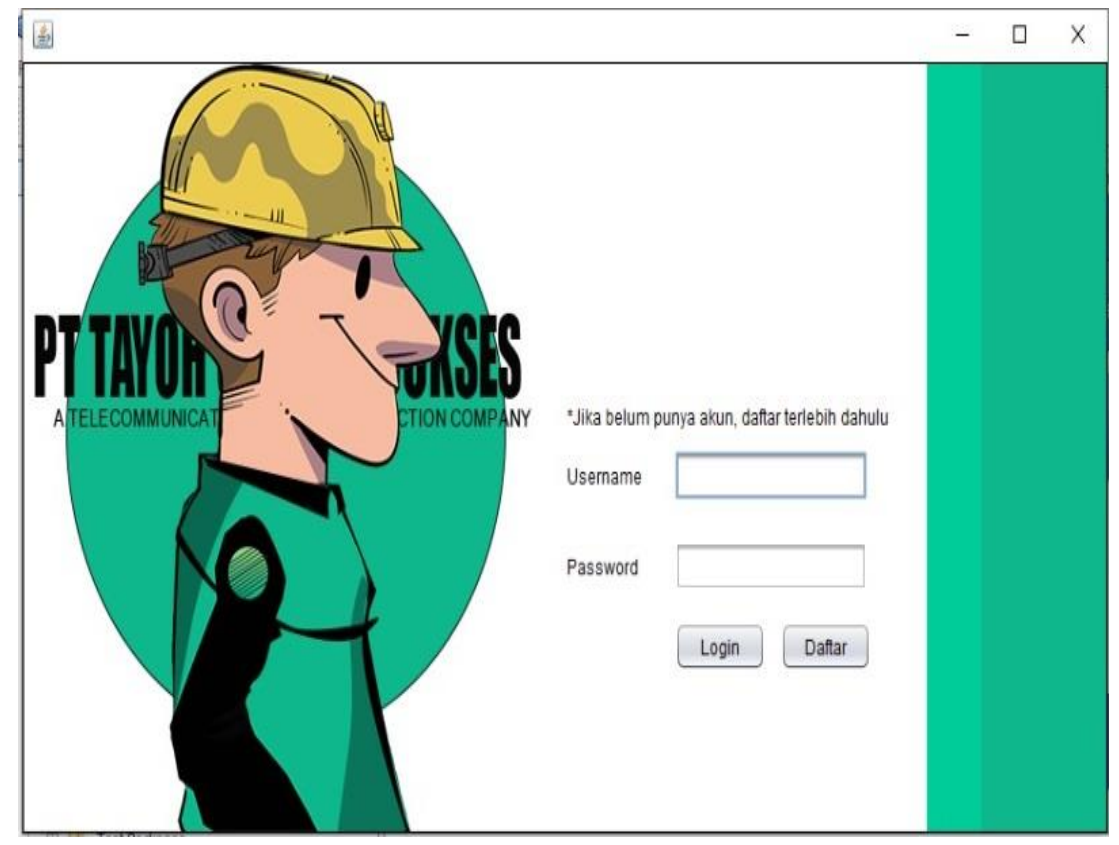

Gambar 4. TampilanMenu Login

Gambar diatas merupakan tampilan menu login untuk mengakses masuk ke menu utama, untuk masuk diperlukan username dan password, apabila belum memiliki akun maka harus daftar terlebih dahulu.

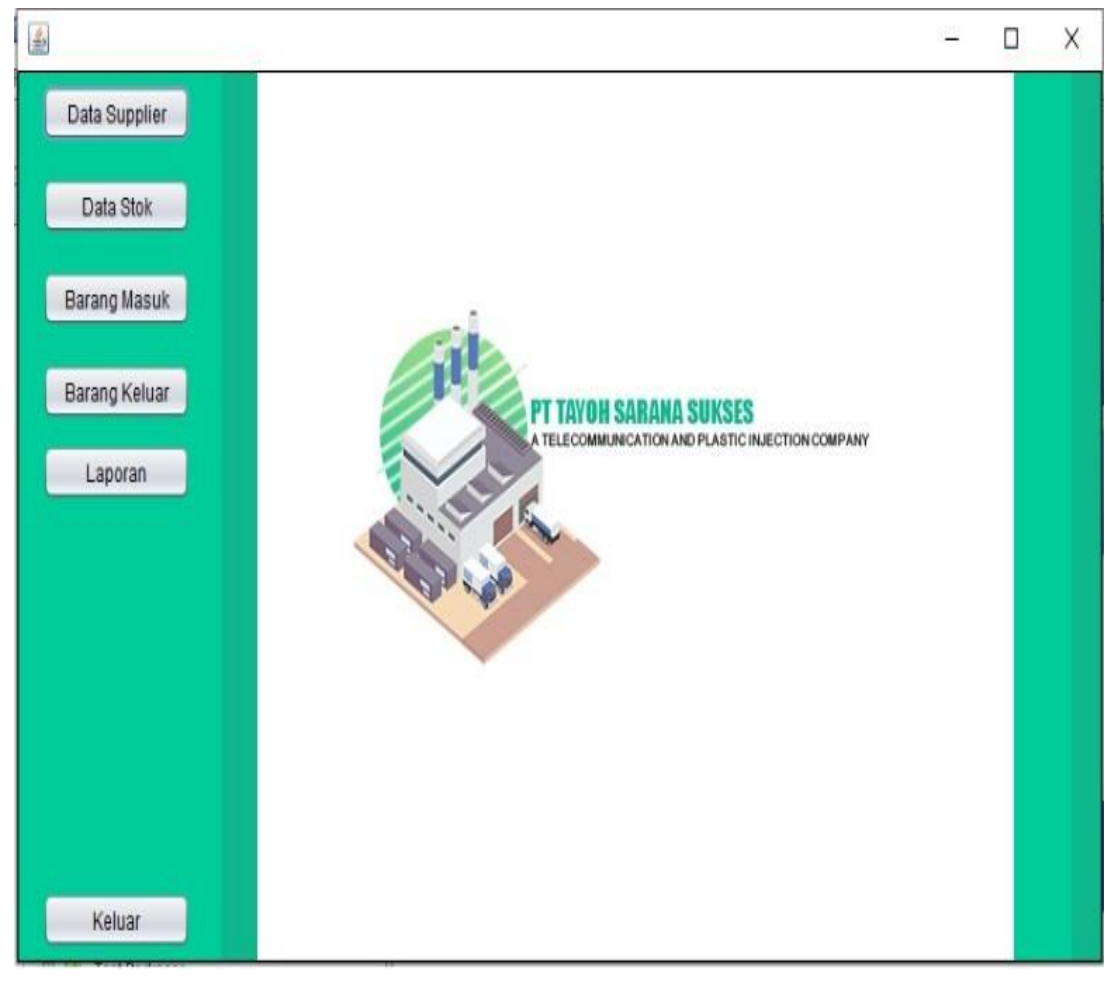

Gambar 5. TampilanMenu Utama

Gambar diatas merupakan tampilan menu utama untuk berpindah dari satu form ke form lainnya. 


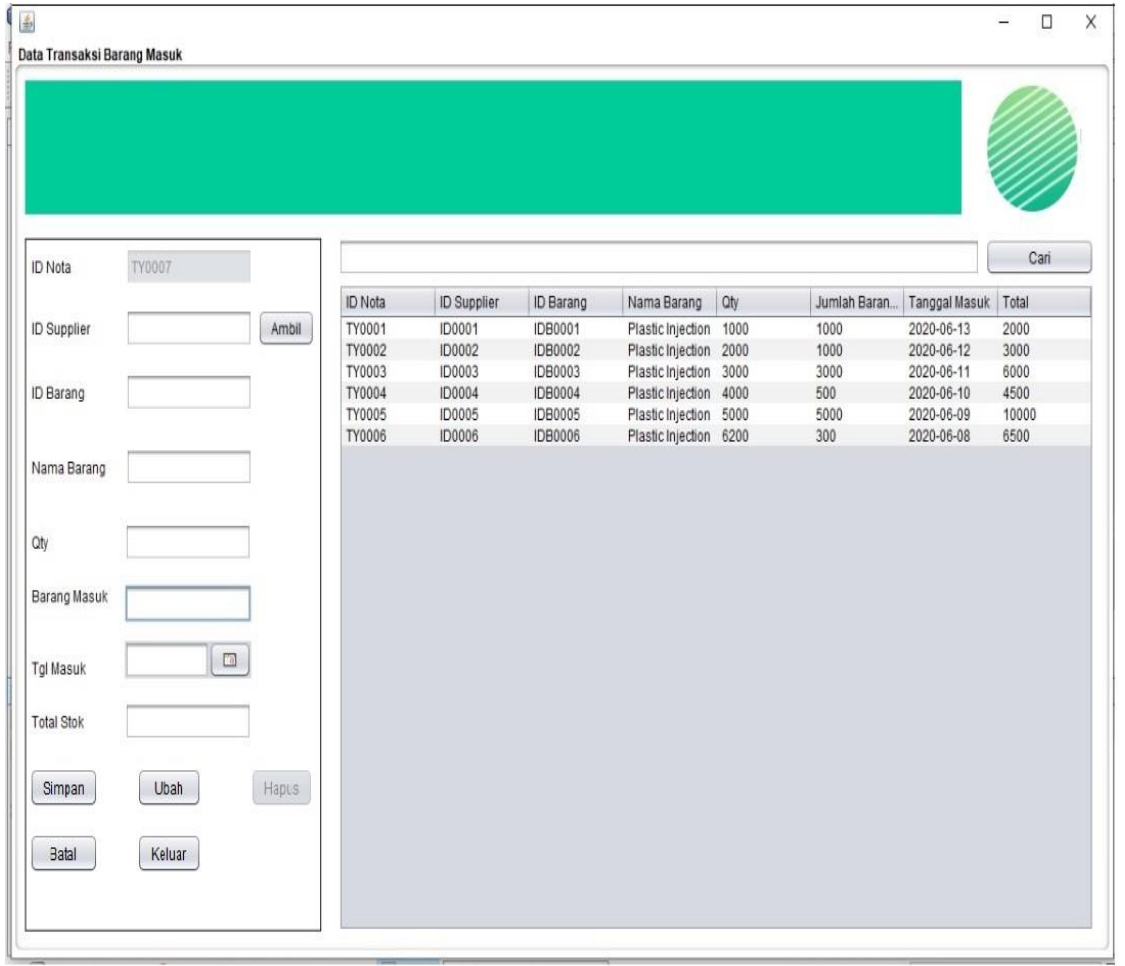

Gambar 6. TampilanForm Barang Masuk

Gambar diatas merupakan tampilan form barang masuk yang digunakan untuk mendata setiap ada transaksi barang masuk yang dating dari supplier.

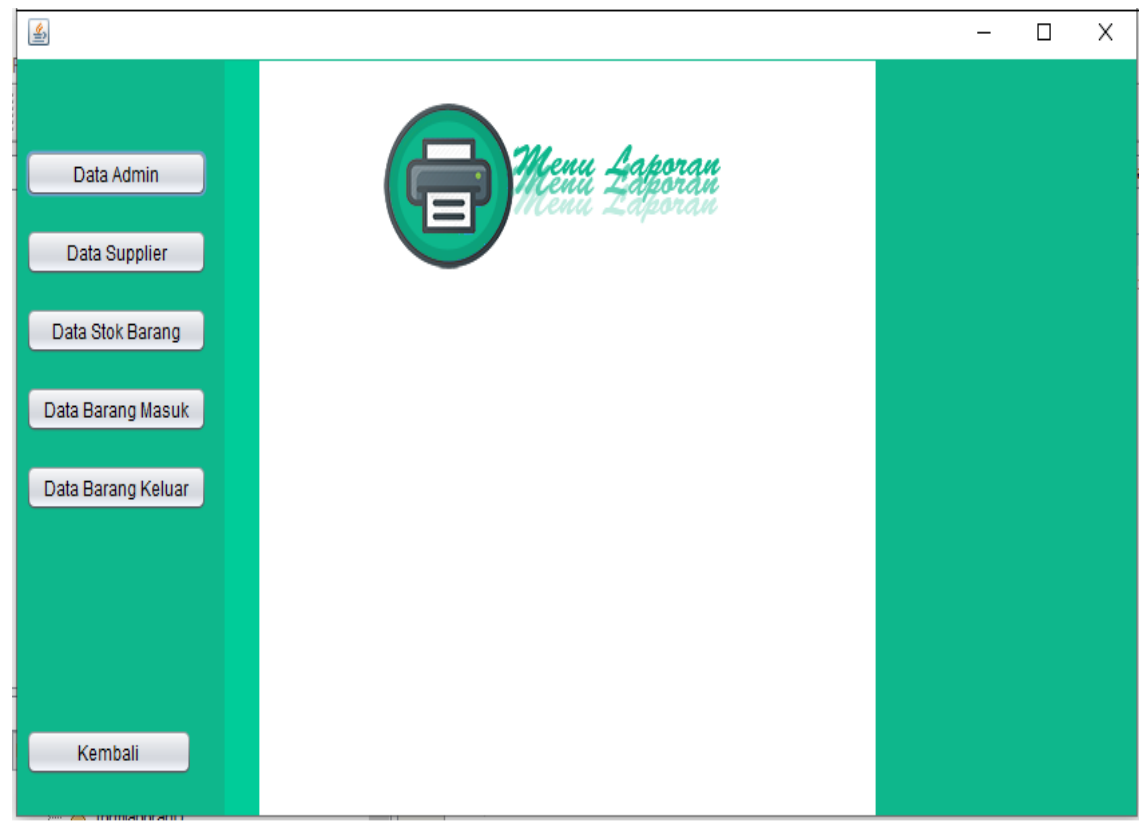

Gambar 7. TampilanMenu Laporan

Gambar diatas merupakan tampilan menu laporan untuk mencetak laporan seperti laporan admin, supplier, stok barang, barang masuk, barang keluar. 


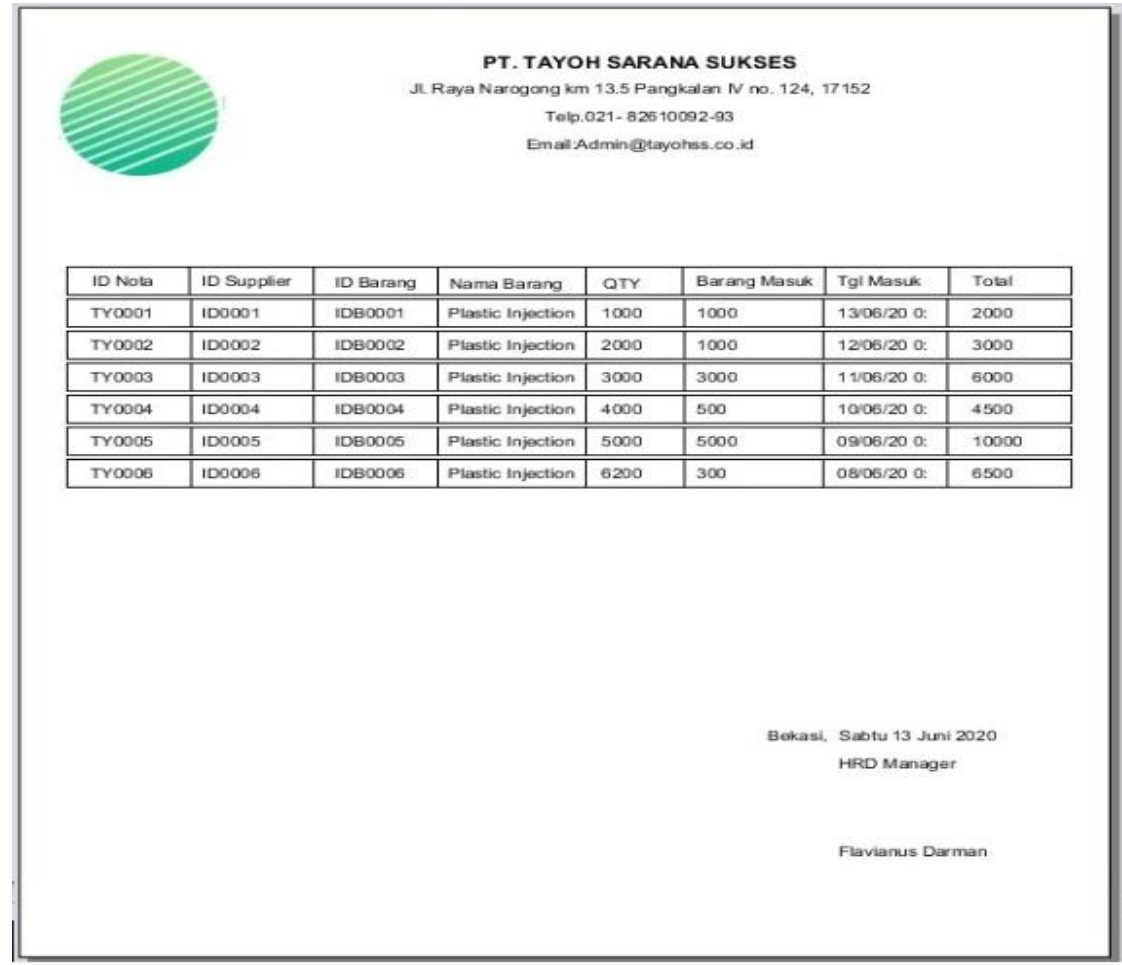

Gambar 8. TampilanLaporan Barang Masuk

Gambar diatas merupakan tampilan laporan keseluruhan barang masuk.

\section{SIMPULAN}

Hasil analisa dan penelitian yang sudah dilakukan maka dapat disimpulkan bahwa Sistem Aplikasi Inventori Bahan Baku pada PT Tayoh Sarana Sukses dapat diterapkan dengan baik dan menjadi solusi untuk memecahkan beberapa masalah yang ada pada perusahaan. Pengunaan sistem inventori bahan baku yang terkomputerisasi membantu perusahaan untuk mengurangi masalah yang sering terjadi, membantu mempercepat proses kerja dan memaksimalkan proses produksi, mempermudah dan mempercepat pendataan bahan baku pada saat barang masuk dari supplier dan barang keluar untuk produksi.

\section{DAFTAR PUSTAKA}

Agus Ristono. (2013). Manajemen Persediaan. Penerbit Graha Ilmu.

Eddy Herjanto. (2010). Manajemen Operasi Edisi Revisi. Gramedia.

Eko Priyo Utomo. (2013). Cara Cepat dan Mudah Belajar Java SE7. Andi.

H.M Alan Jayaatmaja. (2010). Akutansi Biaya. Universitas Widyatama.

Kristanto, A. (2013). Perancangan Sistem Informasi dan Aplikasinya. Gava Media.

Murad. (2013). Membuat Diagram Dan Gambar Teknik Dengan Menggunakan Microsoft Visio 2003. Andi.

Pipin, A. (2013). Kamus Teknologi Informasi. Titian Ilmu.

Roger, S. Pressman, P. D. (2010). Pendekatan Praktisi Rekayasa Perangkat Lunak (7th ed.). Andi.

Sutabri, T. (2012). Analisis Sistem Informasi. Andi.

Wardana. (2010). Menjadi Master PHP Dengan Framework Codeigniter. Elex Media Komputindo. 